\title{
OPEN Author Correction: Cardiovascular risk algorithms in primary care: Results from the DETECT study
}

\begin{abstract}
Tanja B. Grammer, Alexander Dressel, Ingrid Gergei, Marcus E. Kleber $\mathbb{1}$, Ulrich Laufs, Hubert Scharnagl, Uwe Nixdorff, Jens Klotsche, Lars Pieper, David Pittrow, Sigmund Silber, Hans-Ulrich Wittchen \& Winfried März
\end{abstract}

Correction to: Scientific Reports https://doi.org/10.1038/s41598-018-37092-7, published online 31 January 2019

The Acknowledgements section in this Article is incomplete.

"We thank the participants, the study team of the DETECT study, and the laboratory staff at Graz. This work was supported by a grant from the German Federal Ministry of Economics and Energy to the University of Heidelberg, project Coropredict ${ }^{\circledR}$ (grant number 03EFBBWO58). The DETECT (Diabetes Cardiovascular Risk evaluation: Targets and Essential Data for Commitment of Treatment) - study was supported by an unrestricted educational grant from Pfizer GmbH, Karlsruhe, Germany. The sponsors of the study had no influence on the design, analysis or interpretation of data."

should read:

"We thank the participants, the study team of the DETECT study, and the laboratory staff at Graz. This work was supported by a grant from the German Federal Ministry of Economics and Energy to the University of Heidelberg, project Coropredict ${ }^{\circledR}$ (grant number 03EFBBWO58). The DETECT (Diabetes Cardiovascular Risk evaluation: Targets and Essential Data for Commitment of Treatment) - study was supported by an unrestricted educational grant from Pfizer GmbH, Karlsruhe, Germany. The sponsors of the study had no influence on the design, analysis or interpretation of data. We acknowledge financial support by Deutsche Forschungsgemeinschaft within the funding programme Open Access Publishing, by the Baden-Württemberg Ministry of Science, Research and the Arts and by Ruprecht-Karls-Universität Heidelberg."

(c) (i) Open Access This article is licensed under a Creative Commons Attribution 4.0 International Cicense, which permits use, sharing, adaptation, distribution and reproduction in any medium or format, as long as you give appropriate credit to the original author(s) and the source, provide a link to the Creative Commons license, and indicate if changes were made. The images or other third party material in this article are included in the article's Creative Commons license, unless indicated otherwise in a credit line to the material. If material is not included in the article's Creative Commons license and your intended use is not permitted by statutory regulation or exceeds the permitted use, you will need to obtain permission directly from the copyright holder. To view a copy of this license, visit http://creativecommons.org/licenses/by/4.0/.

(C) The Author(s) 2020 